Article

\title{
Effective Medium Method for Chloride Diffusion Coefficient of Mature Fly Ash Cement Paste
}

\author{
Hong Zhou ${ }^{1}$, Xin-Zhu Zhou ${ }^{2, *}$, Jian Zhang ${ }^{2}$ and Jian-Jun Zheng ${ }^{2}$ \\ 1 Architectural Engineering School, Jinhua Polytechnic, Jinhua 321007, China; 20050267@jhc.edu.cn \\ 2 School of Civil Engineering and Architecture, Zhejiang University of Technology, Hangzhou 310023, China; \\ jzhang777777@163.com (J.Z.); jjzheng@zjut.edu.cn (J.-J.Z.) \\ * Correspondence: xzzhou66@zjut.edu.cn
}

Received: 18 February 2019; Accepted: 6 March 2019; Published: 8 March 2019

\begin{abstract}
The chloride diffusion coefficient of concrete plays an essential role in the durability assessment and design of concrete structures built in chloride-laden environments. The purpose of this paper is to present an effective medium method (EMM) for evaluating the chloride diffusion coefficient of mature fly ash cement paste. In this method, a numerical method is used to estimate the degrees of hydration of cement and fly ash. Fly ash cement paste is then modeled as a two-phase composite material, composed of a solid phase and a pore space. By introducing the percolation theory, the EMM is modified to derive the chloride diffusion coefficient of fly ash cement paste in an analytical manner. To verify the EMM, a chloride diffusion test of fly ash cement paste at a curing age of up to 540 days is conducted. It is shown that, within a reasonable fly ash content, a larger fly ash content and/or curing age results in a smaller chloride diffusion coefficient. The chloride diffusion coefficient decreases with a decreasing water/binder ratio. Finally, the validity of the EMM is verified with experimental results.
\end{abstract}

Keywords: fly ash cement paste; chloride diffusion coefficient; effective medium approach; percolation theory

\section{Introduction}

For concrete structures located in chloride-laden environments, the attack of chloride ions becomes the primary cause for the corrosion of reinforcements [1-3]. The penetration of chloride ions into concrete is controlled, to a large extent, by the chloride diffusion coefficient and the chloride binding of cement paste [4,5]. To reduce the chloride diffusion coefficient, various mineral admixtures are usually added to concrete. Fly ash is a byproduct resulted from coal power stations. Chemically, it contains $60-65 \%$ of $\mathrm{SiO}_{2}, 25-30 \%$ of $\mathrm{Al}_{2} \mathrm{O}_{3}$, and $6-15 \%$ of $\mathrm{Fe}_{2} \mathrm{O}_{3}$. Such a special chemical composition makes fly ash exhibit a strong pozzolanic reactivity and improves the microstructure of cement paste particularly after 28 days of curing [6-9]. At a mesoscopic level, concrete is composed of bulk cement paste, interfacial transition zones (ITZs), and aggregates. Essentially, the ITZ is a cement paste with a high water/binder ratio. Compared with the bulk cement paste and ITZ, aggregates are almost impermeable to chloride ions. When the chloride diffusion coefficients of cement pastes with various water/binder ratios are determined, that of concrete can be immediately formulated with a three-phase composite sphere model [10]. Therefore, it is crucial to evaluate the chloride diffusion coefficient of mature fly ash cement paste and to quantify the primary influential factors for the durability assessment and design of cementitious materials.

In experimental investigations, Page et al. [11] designed a measuring device for the chloride diffusion in cement paste and found that the chloride diffusion coefficient is seldom influenced by the chloride concentration. MacDonald and Northwood [4] showed that the chloride diffusion coefficient 
decreased slightly as the sample thickness increased. Castellote et al. [12] demonstrated that, with the migration test, reliable results could be achieved through a greatly shortened measuring process. Tang and Nilsson [13] and Lu [14] also developed rapid tests for measuring the chloride diffusion coefficient of cementitious materials. Ampadu et al. [15] found that fly ash could greatly reduce the chloride diffusion coefficient of cement paste, and the optimum effect was achieved when the replacement ratio of fly ash was $40 \%$. The effects of pre-drying and carbonation on the diffusion of chloride ions into cement paste were also evaluated [16]. Chalabi et al. [17] investigated the effect of the degree of saturation on chloride diffusion in cement paste and showed that a decrease in moisture content from $97 \%$ to $76 \%$ resulted in a higher chloride content. For a given relative humidity at $76 \%$, the penetration depth of chloride ions was larger, while their binding to cement paste became lower. Ramirez-Ortiz et al. [18] used ultrasound to detect the presence and binding of chloride ions in cement paste with a water/cement ratio of 0.55 and found an exponential relationship between energy/amplitude-weighted average frequency and the amount of chloride chemically bound by cement paste. Akhavan and Rajabipour [19] measured the electrical conductivity with electrical impedance spectroscopy to characterize the diffusion coefficient of fiber-reinforced cement paste disks with cracks and showed that the diffusion coefficient was linearly related to the crack volume fraction. Millar et al. [20] investigated the accuracy of laser-induced breakdown spectroscopy in determining the total chloride content in cement paste. In theoretical analyses, Pivonka et al. [21] modeled cement paste as solid spheres dispersed in a pore solution medium and expressed the chloride diffusion coefficient in an analytical manner. Zheng and Zhou [22] presented an effective medium method (EMM) for the chloride diffusion coefficient of two-phase cement paste. In this approach, the Hashin-Shtrikman bounds were satisfied and the typical behaviors close to the percolation threshold were taken care of. With a digital image-based model, Garboczi and Bentz [23] investigated the chloride diffusion characteristics of cement paste. Masi et al. [24] represented the pore space with a network and showed that diffusion mainly takes place in capillary or gel pores, depending on whether the porosity was larger or smaller than the critical value. Liu et al. [25] evaluated the chloride diffusion coefficient by applying a random walk algorithm to the constructed cement paste. Ma et al. [26] estimated the chloride diffusion coefficient of cement paste with a two-scale scheme. Du et al. [27] studied the effect of external mechanical loading on the chloride diffusion coefficient of cement paste with a two-phase sphere model. They showed that the chloride diffusion coefficient decreased with the increase of the compressive volumetric strain but increased with an increasing tensile volumetric strain. Yang et al. [28] proposed a multiscale modeling technique to analyze the transport of chloride ions in cement paste and demonstrated that the contribution of the Stern layer to ion transport was not negligible for pores with a diameter less than $10 \mathrm{~nm}$. Based on the reconstructed microstructure of hardened cement paste, Carrara et al. [29] used a modified Fick's law to simulate the chloride diffusion coefficient and verified the numerical method with experimental results obtained from the literature. Damrongwiriyanupap et al. [30] employ an advanced self-consistent homogenization theory to derive an analytical relationship between the porosity, the diffusion coefficient of the pore solution, and the diffusion coefficient of cement paste. The validity of the relationship was verified with experimental results. From the above literature review, it can be seen that there are two limitations in the current studies. First, most experiments on chloride ion diffusion in cement paste were conducted at an age of 28 days or a few months, and there is a lack of experimental data on the long-term transport properties. Second, there are few analytical or numerical methods reported in the literature for evaluating the chloride diffusion coefficient of fly ash cement paste. Therefore, it is necessary to study the transport properties of mature fly ash cement paste experimentally and theoretically.

The intention of this paper is to propose an EMM for the chloride diffusion coefficient of fly ash cement paste. With fly ash cement paste modeled as a two-phase composite material, the percolation theory is incorporated into the EMM to deduce the chloride diffusion coefficient. Finally, a chloride diffusion test of fly ash cement paste is conducted to investigate the effects of the water/binder ratio, 
the fly ash content, and the curing age on the chloride diffusion coefficient and to verify the validity of the proposed EMM.

\section{Numerical Estimate for Degrees of Hydration of Cement and Fly Ash}

\subsection{Degree of Hydration of Cement}

The hydration of cement is traditionally assumed to proceed through a dissolution and precipitation process. According to Parrot and Killoh [31], the rate of hydration $\mathrm{R}_{\mathrm{i}, \mathrm{t}}$ of a particular clinker phase in cement is expressed as the following three equations:

$$
\begin{gathered}
R_{i, t}=\frac{K_{1}}{N_{1}}\left(1-\alpha_{i, t}\right)\left[-\ln \left(1-\alpha_{i, t}\right)\right]^{1-N_{1}} \text { for nucleation and growth, } \\
R_{i, t}=\frac{K_{2}\left(1-\alpha_{i, t}\right)^{2 / 3}}{1-\left(1-\alpha_{i, t}\right)^{1 / 3}} \text { for diffusion, and } \\
R_{i, t}=K_{3}\left(1-\alpha_{i, t}\right)^{N_{3}} \text { for formation of hydration shell, }
\end{gathered}
$$

where $\alpha_{i, t}$ is the degree of hydration of clinker phase $i\left(C_{3} S, C_{2} S, C_{3} A\right.$, and $\left.C_{4} A F\right)$ at time $t ; K_{1}, N_{1}$, $\mathrm{K}_{2}, \mathrm{~K}_{3}$, and $\mathrm{N}_{3}$ are empirical constants as listed in Table 1 [31]; and the lowest value of $\mathrm{R}_{\mathrm{i}, \mathrm{t}}$ at time $t$ calculated from Equations (1)-(3) is selected to evaluate the instantaneous degree of hydration. Thus, the degree of hydration of cement $\alpha_{c}$ is taken as the weighted average of the degrees of hydration of the clinker phases.

Table 1. The kinetic parameters of clinker phases at different hydration stages.

\begin{tabular}{ccccc}
\hline \multirow{2}{*}{ Kinetic Parameter } & \multicolumn{4}{c}{ Clinker Phase } \\
\cline { 2 - 5 } & $\mathbf{C}_{3} \mathbf{S}$ & $\mathbf{C}_{2} \mathbf{S}$ & $\mathbf{C}_{3} \mathbf{A}$ & $\mathbf{C}_{4} \mathbf{A F}$ \\
\hline $\mathrm{K}_{1}$ & 1.5 & 0.5 & 1.0 & 0.37 \\
$\mathrm{~N}_{1}$ & 0.7 & 1.0 & 0.85 & 0.7 \\
$\mathrm{~K}_{2}$ & 3.3 & 5.0 & 3.2 & 3.7 \\
$\mathrm{~K}_{3}$ & 0.05 & 0.006 & 0.04 & 0.015 \\
$\mathrm{~N}_{3}$ & 1.1 & 0.2 & 1.0 & 0.4 \\
\hline
\end{tabular}

\subsection{Degree of Hydration of Fly Ash}

In estimating the degree of hydration of fly ash $\alpha_{\mathrm{f}}$, a unit volume of fly ash cement paste is considered, which includes $\mathrm{c}_{0} \mathrm{~g}$ of cement, $\mathrm{f}_{0} \mathrm{~g}$ of fly ash, and $\mathrm{w}_{0} \mathrm{~g}$ of water. The densities of cement, fly ash, and water are denoted by $\rho_{\mathrm{c}}, \rho_{\mathrm{f}}$, and $\rho_{\mathrm{w}}$, respectively. According to Wang and Lee [32], $\alpha_{\mathrm{f}}$ is determined from the following equation:

$$
\frac{\mathrm{d} \alpha_{\mathrm{f}}}{\mathrm{dt}}=\frac{3 \mathrm{~m}_{\mathrm{CH}}(\mathrm{t})}{\mathrm{f}_{0} \mathrm{v}_{\mathrm{f}} \mathrm{r}_{\mathrm{f} 0} \rho_{\mathrm{f}}\left[\left(1 / \mathrm{k}_{\mathrm{df}}-\mathrm{r}_{\mathrm{f} 0} / \mathrm{D}_{\mathrm{ef}}\right)+\left(\mathrm{r}_{\mathrm{f} 0} / \mathrm{D}_{\mathrm{ef}}\right)\left(1-\alpha_{\mathrm{f}}\right)^{-1 / 3}+\left(1 / \mathrm{k}_{\mathrm{rf}}\right)\left(1-\alpha_{\mathrm{f}}\right)^{-2 / 3}\right]} .
$$

In Equation (4), $\mathrm{m}_{\mathrm{CH}}(\mathrm{t})$ is the $\mathrm{CH}$ mass, $\mathrm{v}_{\mathrm{f}}$ is the stoichiometric mass ratio of $\mathrm{CH}$ to fly ash, $\mathrm{r}_{\mathrm{f} 0}$ is the radius of fly ash particles before hydration, $k_{\mathrm{rf}}$ is the reaction rate coefficient, and $k_{\mathrm{df}}$ and $\mathrm{D}_{\mathrm{ef}}$ are defined as

$$
\begin{gathered}
k_{d f}=\frac{B_{f}}{\alpha_{f}^{1.5}}+C_{f}\left(r_{f 0}-r_{f t}\right)^{4} \text { and } \\
D_{e f}=D_{e f 0} \ln \left(1 / \alpha_{f}\right),
\end{gathered}
$$

where $D_{\text {efo }}$ is the initial diffusion coefficient, $r_{f t}$ is the radius of fly ash particles at time $t$, and $B_{f}$ and $\mathrm{C}_{\mathrm{f}}$ are two coefficients. The empirical coefficients included in Equations (4)-(6) are listed in Table 2. 
Since the hydration product $\mathrm{CH}$ is consumed in the second hydration reaction of fly ash, $\mathrm{m}_{\mathrm{CH}}(\mathrm{t}) \mathrm{can}$ be expressed, in terms of $\alpha_{\mathrm{f}}$ and $\alpha_{\mathrm{c}}$, as [33]

$$
\mathrm{m}_{\mathrm{CH}}(\mathrm{t})=\left(1.32 \mathrm{f}_{\mathrm{C}, \mathrm{c}}-1.85 \mathrm{f}_{\mathrm{S}, \mathrm{c}}-2.91 \mathrm{f}_{\mathrm{A}, \mathrm{c}}-0.93 \mathrm{f}_{\mathrm{F}, \mathrm{c}}\right) \mathrm{c}_{0} \alpha_{\mathrm{c}}-\left(1.85 \gamma_{\mathrm{S}} \mathrm{f}_{\mathrm{S}, \mathrm{f}}+2.91 \gamma_{\mathrm{A}} \mathrm{f}_{\mathrm{A}, \mathrm{f}}\right) \mathrm{f}_{0} \alpha_{\mathrm{f}}
$$

where $\mathrm{f}_{\mathrm{C}, \mathrm{c}}, \mathrm{f}_{\mathrm{S}, \mathrm{c}}, \mathrm{f}_{\mathrm{A}, \mathrm{c}}$, and $\mathrm{f}_{\mathrm{F}, \mathrm{c}}$ are the respective mass fractions of $\mathrm{CaO}, \mathrm{SiO}_{2}, \mathrm{Al}_{2} \mathrm{O}_{3}$, and $\mathrm{Fe}_{2} \mathrm{O}_{3}$ in cement; $\mathrm{f}_{\mathrm{S}, \mathrm{f}}$ and $\mathrm{f}_{\mathrm{A}, \mathrm{f}}$ are the respective mass fractions of $\mathrm{SiO}_{2}$ and $\mathrm{Al}_{2} \mathrm{O}_{3}$ in fly ash, and the coefficients $\gamma_{\mathrm{S}}$ and $\gamma_{\mathrm{A}}$ are both taken as $0.82[33]$.

Table 2. The parameters in the hydration model of fly ash.

\begin{tabular}{cccc}
\hline $\mathbf{B}_{\mathrm{f}}(\mathbf{c m} / \mathbf{h})$ & $\mathbf{C}_{\mathbf{f}}\left(\mathbf{c m} /\left(\mathrm{cm}^{4} \cdot \mathbf{h}\right)\right)$ & $\mathbf{k}_{\mathbf{r f}}(\mathbf{c m} / \mathbf{h})$ & $\mathbf{D}_{\text {ef0 }}\left(\mathrm{cm}^{2} / \mathbf{h}\right)$ \\
\hline $2.51 \times 10^{-9}$ & $1.00 \times 10^{15}$ & $1.71 \times 10^{-6}$ & $8.58 \times 10^{-8}$ \\
\hline
\end{tabular}

\subsection{Experimental Verification}

To assess the computational accuracy of the numerical estimate, the experimental results of Haha et al. [34] are considered. In their experiment, the fly ash was composed of $50 \%$ of $\mathrm{SiO}_{2}$ and $23.9 \%$ of $\mathrm{Al}_{2} \mathrm{O}_{3}$. The average particle diameter, density, and mass fraction were $14 \mu \mathrm{m}, 2.74 \mathrm{~g} / \mathrm{cm}^{3}$, and $35 \%$, respectively. $\mathrm{w} / \mathrm{b}$ was $0.5 . \alpha_{\mathrm{f}}$ was determined with a selective dissolution technique and backscattered electron image analysis. When the curing age was $1,7,28$, and 90 days, $\alpha_{\mathrm{f}}$ was obtained as $0.045,0.085$, 0.165 , and 0.24 , respectively. With the same parameters as adopted in the experiment, $\alpha_{\mathrm{f}}$ is estimated from Equation (4) as shown in Figure 1, which indicates a good agreement between the numerical estimate and the experimental results with a correlation coefficient of 0.996 . Therefore, the degree of hydration of fly ash can be estimated with reasonable accuracy.

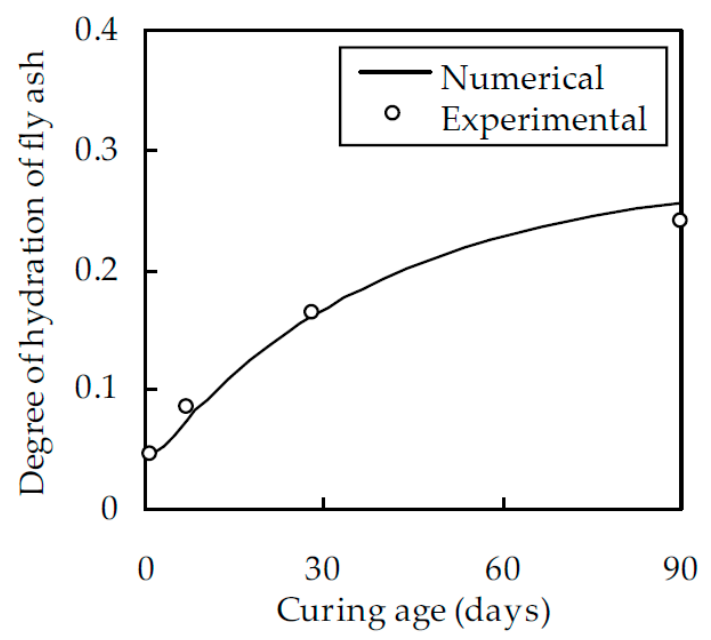

Figure 1. A comparison between the numerical estimate and experimental results of Haha et al. [34].

\section{EMM for Chloride Diffusion Coefficient of Fly Ash Cement Paste}

\subsection{Volume Fractions of Solid Phase and Pore Space}

It is well-known that Portland cement paste is a multiphase composite material, mainly composed of unhydrated cement, C-S-H, CH, and capillary pores. Gel pores are located within C-S-H and exert minor influence on chloride diffusion. By contrast, capillary pores are larger and play a major role in penetrating chloride ions into cement paste. When fly ash incorporates into cement, it reacts with $\mathrm{CH}$ to form additional gel pores. Therefore, as far as the diffusion of chloride ions in fly ash cement paste is concerned, it can be simplified as a two-phase medium: solid phase and pore space. According to Hansen [35] and Wang and Lee [32], at complete hydration, $1 \mathrm{~g}$ of cement will consume $0.36 \mathrm{~cm}^{3}$ of 
chemically bound water and form $0.19 \mathrm{~cm}^{3}$ of gel water, while $1 \mathrm{~g}$ of fly ash will consume $0.10 \mathrm{~g}$ of chemically bound water and form $0.15 \mathrm{~g}$ of gel water. Since the specific volumes of chemically bound water and gel water are 0.75 and $1 \mathrm{~cm}^{3} / \mathrm{g}$, respectively, the volume fractions of gel ( $\mathrm{f}_{\text {gel }}$ ) and capillary $\left(f_{\text {cap }}\right)$ pores are given by

$$
\begin{gathered}
\mathrm{f}_{\text {gel }}=\frac{0.19 \mathrm{c}_{0} \alpha_{\mathrm{c}}+0.15 \mathrm{f}_{0} \alpha_{\mathrm{f}}}{\mathrm{c}_{0} / \rho_{\mathrm{c}}+\mathrm{f}_{0} / \rho_{\mathrm{f}}+\mathrm{w}_{0} / \rho_{\mathrm{w}}} \text { and } \\
\mathrm{f}_{\text {cap }}=\frac{\mathrm{w}_{0} / \rho_{\mathrm{w}}-0.36 \mathrm{c}_{0} \alpha_{\mathrm{c}}-0.075 \mathrm{f}_{0} \alpha_{\mathrm{f}}}{\mathrm{c}_{0} / \rho_{\mathrm{c}}+\mathrm{f}_{0} / \rho_{\mathrm{f}}+\mathrm{w}_{0} / \rho_{\mathrm{w}}} .
\end{gathered}
$$

Thus, the volume fractions of the pore space $\left(f_{p}\right)$ and the solid phase $\left(f_{s}\right)$ are

$$
\begin{gathered}
\mathrm{f}_{\mathrm{p}}=\mathrm{f}_{\mathrm{gel}}+\mathrm{f}_{\text {cap }} \\
=\frac{\mathrm{w}_{0} / \rho_{\mathrm{w}}-0.17 \mathrm{c}_{0} \alpha_{\mathrm{c}}+0.075 \mathrm{f}_{0} \alpha_{\mathrm{f}}}{\mathrm{c}_{0} / \rho_{\mathrm{c}}+\mathrm{f}_{0} / \rho_{\mathrm{f}}+\mathrm{w}_{0} / \rho_{\mathrm{w}}} \text { and } \\
\mathrm{f}_{\mathrm{s}}=1-\mathrm{f}_{\mathrm{p}} \\
=\frac{\mathrm{c}_{0}\left(1 / \rho_{\mathrm{c}}+0.17 \alpha_{\mathrm{c}}\right)+\mathrm{f}_{0}\left(1 / \rho_{\mathrm{f}}-0.075 \alpha_{\mathrm{f}}\right)}{\mathrm{c}_{0} / \rho_{\mathrm{c}}+\mathrm{f}_{0} / \rho_{\mathrm{f}}+\mathrm{w}_{0} / \rho_{\mathrm{w}}} .
\end{gathered}
$$

To verify the validity of the empirical formulae, the experimental results of $\mathrm{Yu}$ [36] are considered. In his test, $\mathrm{w} / \mathrm{b}$ was 0.4 and $\mathrm{m}_{\mathrm{f}}$ were $30 \%$ and $50 \%$, respectively. The porosity was measured at curing ages of 7, 28, 90, 180, and 360 days as shown in Figure 2, which shows that the empirical formula agrees well with the experimental results. The correlation coefficient between them is 0.952 and 0.966 for a given fly ash content $\mathrm{m}_{\mathrm{f}}$ at $30 \%$ and $50 \%$ by mass, respectively. Therefore, the porosity of fly ash cement paste can be estimated from the empirical formula with reasonable accuracy.

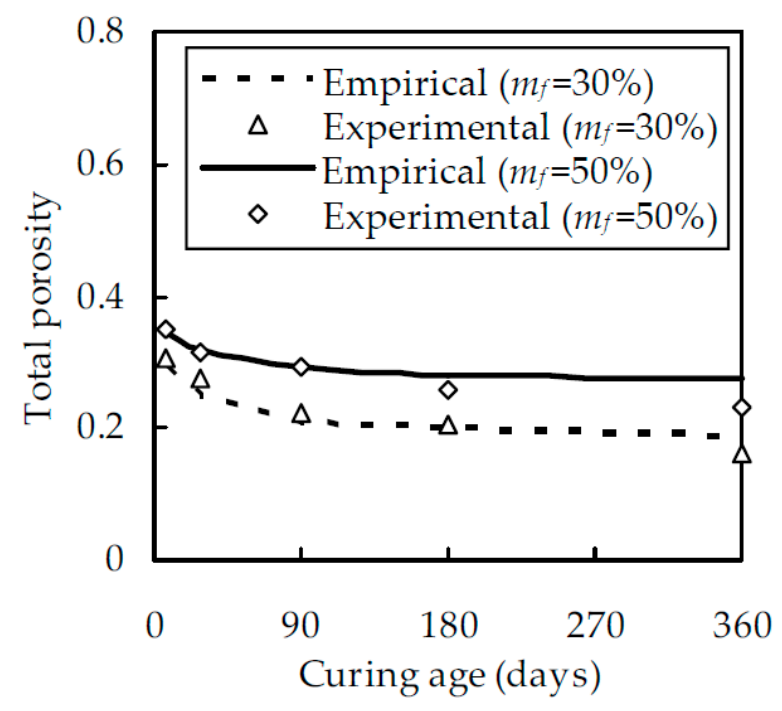

Figure 2. A comparison between the empirical formula and experimental results of $\mathrm{Yu}$ [36].

\subsection{Chloride Diffusion Coefficient of Fly Ash Cement Paste}

In evaluating the chloride diffusion coefficient, it is assumed in this paper that two-phase fly ash cement paste is an isotropic material and that gel and capillary pores are spheroids with aspect ratio $\mu$. According to the EMM theory, the chloride diffusion coefficient $\mathrm{D}_{\mathrm{fc}}$ of fly ash cement paste can be expressed as [37]

$$
9 f_{s} \frac{D_{s}-D_{f c}}{2 D_{f c}+D_{s}}+f_{p}\left[\frac{D_{p}-D_{f c}}{D_{f c}+\lambda\left(D_{p}-D_{f c}\right)}+4 \frac{D_{p}-D_{f c}}{2 D_{f c}+(1-\lambda)\left(D_{p}-D_{f c}\right)}\right]=0,
$$


where $D_{p}$ and $D_{s}$ are the chloride diffusion coefficients of the pore solution and the solid phase, respectively, and the depolarization factor $\lambda$ is defined in terms of $\mu$ as [37]

$$
\lambda=\left\{\begin{array}{c}
\frac{1}{1-\mu^{2}}\left[1-\frac{\mu}{2 \sqrt{\mu^{2}-1}} \ln \left(\frac{\mu+\sqrt{\mu^{2}-1}}{\mu-\sqrt{\mu^{2}-1}}\right)\right], \mu>1 \\
\frac{1}{3-\mu^{2}}\left[1-\frac{\mu}{\sqrt{1-\mu^{2}}} \tan ^{-1}\left(\frac{\sqrt{1-\mu^{2}}}{\mu}\right)\right], \mu<1
\end{array} .\right.
$$

Compared with the pore solution, the solid phase is almost impermeable to chloride ions, and therefore, $D_{s}$ can be set to be zero. Thus, Equation (12) reduces to

$$
\frac{D_{\mathrm{p}}-\mathrm{D}_{\mathrm{fc}}}{\mathrm{D}_{\mathrm{fc}}+\lambda\left(\mathrm{D}_{\mathrm{p}}-\mathrm{D}_{\mathrm{fc}}\right)}+4 \frac{\mathrm{D}_{\mathrm{p}}-\mathrm{D}_{\mathrm{fc}}}{2 \mathrm{D}_{\mathrm{fc}}+(1-\lambda)\left(\mathrm{D}_{\mathrm{p}}-\mathrm{D}_{\mathrm{fc}}\right)}=\frac{9 \mathrm{f}_{\mathrm{s}}}{2 \mathrm{f}_{\mathrm{p}}}
$$

After cement and fly ash are mixed with water, capillary pores in fly ash cement paste are percolated before the initial setting time. After the initial setting time, the hydration products and gel pores become a percolating network spanning fly ash cement paste. Therefore, the pore space is a percolating phase with zero percolation threshold. It should be pointed out that Equation (14) is not applicable for a percolating pore space and breaks down for fly ash cement paste. Therefore, it is necessary to modify Equation (14) by taking into account the percolation characteristics close to the percolation threshold. According to the percolation theory [38], the chloride diffusion coefficient of fly ash cement paste near zero percolation threshold is of the form

$$
\mathrm{D}_{\mathrm{fc}}=\mathrm{D}_{\mathrm{p}} \mathrm{f}_{\mathrm{p}}^{\mathrm{n}}
$$

where $\mathrm{n}$ is a percolation exponent. In view of Eqution (15), Equation (14) can be modified as

$$
\frac{\mathrm{D}_{\mathrm{p}}^{1 / \mathrm{n}}-\mathrm{D}_{\mathrm{fc}}^{1 / \mathrm{n}}}{\mathrm{D}_{\mathrm{fc}}^{1 / \mathrm{n}}+\lambda\left(\mathrm{D}_{\mathrm{p}}^{1 / \mathrm{n}}-\mathrm{D}_{\mathrm{fc}}^{1 / \mathrm{n}}\right)}+4 \frac{\mathrm{D}_{\mathrm{p}}^{1 / \mathrm{n}}-\mathrm{D}_{\mathrm{fc}}^{1 / \mathrm{n}}}{2 \mathrm{D}_{\mathrm{fc}}^{1 / \mathrm{n}}+(1-\lambda)\left(\mathrm{D}_{\mathrm{p}}^{1 / \mathrm{n}}-\mathrm{D}_{\mathrm{fc}}^{1 / \mathrm{n}}\right)}=\frac{9 \mathrm{f}_{\mathrm{s}}}{2 \mathrm{f}_{\mathrm{p}}} .
$$

Since $\mathrm{D}_{\mathrm{p}}>0$, Equation (16) reduces to

$$
\frac{1-\left(\mathrm{D}_{\mathrm{fc}} / \mathrm{D}_{\mathrm{p}}\right)^{1 / \mathrm{n}}}{\left(\mathrm{D}_{\mathrm{fc}} / \mathrm{D}_{\mathrm{p}}\right)^{1 / \mathrm{n}}+\lambda\left[1-\left(\mathrm{D}_{\mathrm{fc}} / \mathrm{D}_{\mathrm{p}}\right)^{1 / \mathrm{n}}\right]}+4 \frac{1-\left(\mathrm{D}_{\mathrm{fc}} / \mathrm{D}_{\mathrm{p}}\right)^{1 / \mathrm{n}}}{2\left(\mathrm{D}_{\mathrm{fc}} / \mathrm{D}_{\mathrm{p}}\right)^{1 / \mathrm{n}}+(1-\lambda)\left[1-\left(\mathrm{D}_{\mathrm{fc}} / \mathrm{D}_{\mathrm{p}}\right)^{1 / \mathrm{n}}\right]}=\frac{9 \mathrm{f}_{\mathrm{s}}}{2 \mathrm{f}_{\mathrm{p}}}
$$

Solving Equation (17) for $\left(\mathrm{D}_{\mathrm{fc}} / \mathrm{D}_{\mathrm{p}}\right)^{1 / \mathrm{n}}$ gives

$$
\frac{\mathrm{D}_{\mathrm{fc}}^{1 / \mathrm{n}}}{\mathrm{D}_{\mathrm{p}}^{1 / \mathrm{n}}}=\frac{4-\mathrm{k}+(\mathrm{k}-6) \lambda-2 \mathrm{k} \lambda^{2}+\sqrt{36-4 \mathrm{k}+\mathrm{k}^{2}+\left(12 \mathrm{k}-6 \mathrm{k}^{2}\right) \lambda+9 \mathrm{k}^{2} \lambda^{2}}}{10+2 \mathrm{k}-6 \lambda-2 \mathrm{k} \lambda^{2}},
$$

where $\mathrm{k}$ is defined as

$$
\mathrm{k}=\frac{9 \mathrm{f}_{\mathrm{s}}}{2 \mathrm{f}_{\mathrm{p}}} .
$$

Thus, $\mathrm{D}_{\mathrm{fc}}$ can be evaluated from Equation (18).

\section{Experimental Verification and Discussions}

\subsection{Materials, Methods, and Results}

To verify the EMM for the chloride diffusion coefficient of fly ash cement paste, a chloride diffusion text was conducted in this study. In the test, fly ash cement paste was made with an ordinary Portland 
cement of grade P.O 42.5 and a fly ash of grade II. The apparent densities of the cement and fly ash were 3150 and $2300 \mathrm{~kg} / \mathrm{m}^{3}$, respectively, and the chemical compositions are listed in Table 3. The water/binder ratio $\mathrm{w} / \mathrm{b}$ was selected as $0.4,0.5$, and 0.6 . For each $\mathrm{w} / \mathrm{b}$, one mix was cast with the cement, while the other three mixes were cast by replacing $\mathrm{m}_{\mathrm{f}}=10 \%, 20 \%$, and $30 \%$ by mass of the cement with the fly ash. Tap water with a $\mathrm{pH}$ value of 6.5 was used for mixing and curing the fly ash cement paste.

Table 3. Chemical compositions of fly ash and cement.

\begin{tabular}{|c|c|c|c|c|c|c|c|c|c|}
\hline Material & $\begin{array}{c}\mathrm{CaO} \\
(\%)\end{array}$ & $\begin{array}{l}\mathrm{SiO}_{2} \\
(\%)\end{array}$ & $\underset{(\%)}{\mathrm{Al}_{2} \mathrm{O}_{3}}$ & $\begin{array}{c}\mathrm{Fe}_{2} \mathrm{O}_{3} \\
(\%)\end{array}$ & $\underset{(\%)}{\mathrm{MgO}}$ & $\begin{array}{l}\mathrm{SO}_{3} \\
(\%)\end{array}$ & $\begin{array}{c}\mathrm{K}_{2} \mathrm{O} \\
(\%)\end{array}$ & $\underset{(\%)}{\mathrm{Na}_{2} \mathrm{O}}$ & $\begin{array}{c}\text { Loss of Ignition } \\
(\%)\end{array}$ \\
\hline Fly ash & 5.40 & 47.00 & 31.30 & 4.40 & 0.49 & 0.77 & 0.90 & 0.78 & 3.22 \\
\hline Cement & 64.40 & 20.36 & 4.96 & 3.17 & 2.09 & 1.98 & 0.64 & 0.14 & 1.27 \\
\hline
\end{tabular}

Compared with concrete, cement paste is more uniform and the measured chloride diffusion coefficients for the same mix have a smaller scatter. Therefore, for each mix, three identical cylindrical specimens $100 \mathrm{~mm}$ thick and $100 \mathrm{~mm}$ in diameter were made to measure the average chloride diffusion coefficient. After $24 \mathrm{~h}$ of casting, the demolded specimens were cured in the laboratory. The temperature and relative humidity were $20 \pm 1{ }^{\circ} \mathrm{C}$ and $95 \pm 1 \%$, respectively. At a given curing age, the specimens were taken out from the curing room and the mid-part with a thickness of $50 \mathrm{~mm}$ was cut off. The chloride diffusion coefficient was measured with the accelerated method proposed by Lu [14], as shown in Figures 3-5.

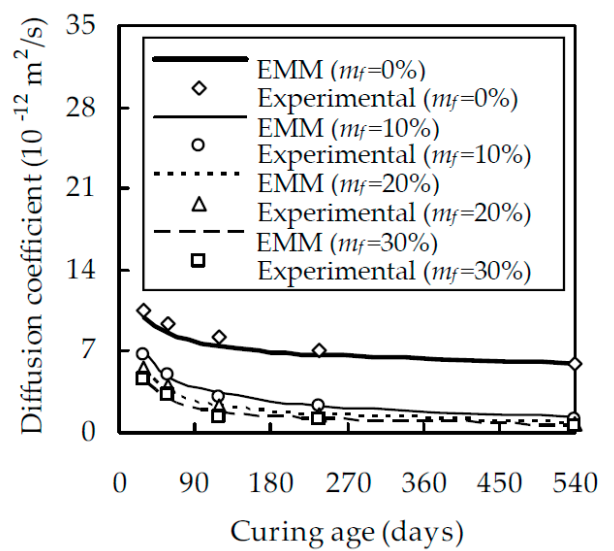

Figure 3. The relationship between $\mathrm{D}_{\mathrm{fc}}$ and $\mathrm{t}$ for fly ash cement paste with $\mathrm{w} / \mathrm{b}$ of 0.5 .

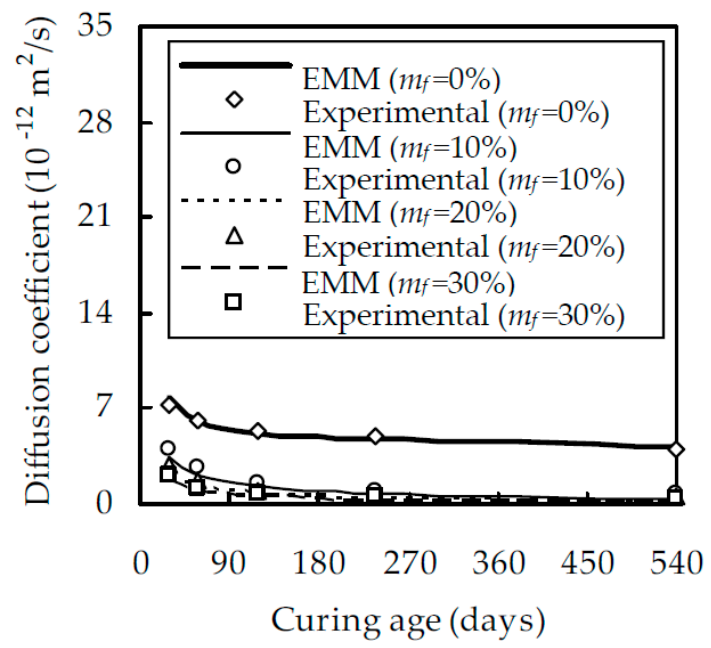

Figure 4. Relationship between $\mathrm{D}_{\mathrm{fc}}$ and $\mathrm{t}$ for fly ash cement paste with $\mathrm{w} / \mathrm{b}$ of 0.4 . 


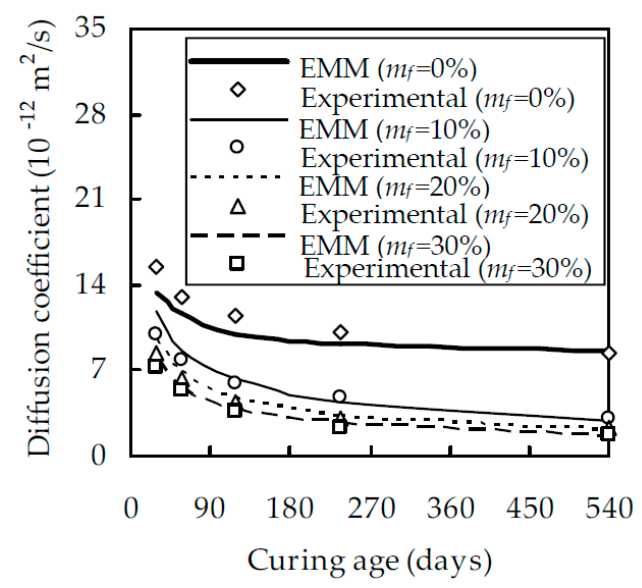

Figure 5. Relationship between $\mathrm{D}_{\mathrm{fc}}$ and $\mathrm{t}$ for fly ash cement paste with $\mathrm{w} / \mathrm{b}$ of 0.6.

When $\mathrm{w} / \mathrm{b}$ is 0.5 , the relationship between the chloride diffusion coefficient $\mathrm{D}_{\mathrm{fc}}$ and the curing age $t$ is shown in Figure 3 for different fly ash contents $m_{f}$, which indicates that, at a given $t, D_{f c}$ decreases with the increase of $m_{f}$. The reason for this is that, within a reasonable value of $m_{f}$, fly ash particles uniformly distribute in the cement paste, fill in the gel and capillary pores, and improve the pore structure. When $\mathrm{m}_{\mathrm{f}}$ increases from $0 \%$ to $10 \%, \mathrm{D}_{\mathrm{fc}}$ decreases evidently. However, when $\mathrm{m}_{\mathrm{f}}$ is larger than $10 \%$, the effect of fly ash on $\mathrm{D}_{\mathrm{fc}}$ reduces gradually. For a given $\mathrm{t}$ at $28,58,118,238$, and 540 days, $\mathrm{D}_{\mathrm{fc}}$ at $\mathrm{m}_{\mathrm{f}}=10 \%$ is smaller than that at $\mathrm{m}_{\mathrm{f}}=0 \%$ by $36.1 \%, 46.7 \%, 63.1 \%, 66.3 \%$, and $79.4 \%$, while $\mathrm{D}_{\mathrm{fc}}$ at $\mathrm{m}_{\mathrm{f}}=30 \%$ is smaller than that at $\mathrm{m}_{\mathrm{f}}=10 \%$ by $32.9 \%, 43.4 \%, 53.8 \%, 62.3 \%$, and $49.6 \%$, respectively. Figure 3 also demonstrates that, for fly ash cement pastes with $\mathrm{m}_{\mathrm{f}}=20 \%$ and $30 \%$, their chloride diffusion coefficients are very close, especially at the later ages of curing, which is consistent with the results of Oh and Jang [39]. It should also be pointed out that, although $\mathrm{D}_{\mathrm{fc}}$ decreases with increasing $\mathrm{m}_{\mathrm{f}}$, an excessively large $\mathrm{m}_{\mathrm{f}}$ will appreciably reduce the degree of hydration of fly ash and second hydration products. As expected, $\mathrm{D}_{\mathrm{fc}}$ decreases with an increase in curing age $\mathrm{t}$. When $\mathrm{m}_{\mathrm{f}}$ is $0 \%, 10 \%, 20 \%$, and $30 \%, \mathrm{D}_{\mathrm{fc}}$ at 540 days is smaller than that at 28 days by $43.1 \%, 81.7 \%, 84.9 \%$, and $86.2 \%$, respectively. This is due to the fact that the pozzolanic reaction of fly ash mainly takes place after 28 days [40]. With the pozzolanic reaction, a great quantity of second $\mathrm{C}-\mathrm{S}-\mathrm{H}$ is produced, the size of large capillary pores is reduced, and the resistance to chloride ingress is enhanced. When $\mathrm{w} / \mathrm{b}$ is equal to 0.4 and 0.6, the relationship between $D_{\mathrm{fc}}$ and $t$ is shown in Figures 4 and 5, respectively. A comparison of Figures 3-5 shows that, for a given $m_{\mathrm{f}}$ and $t, D_{\mathrm{fc}}$ decreases with a decreasing $\mathrm{w} / \mathrm{b}$. When $\mathrm{t}$ is 540 days and $\mathrm{w} / \mathrm{b}$ decreases from 0.6 to 0.4 , $\mathrm{D}_{\mathrm{fc}}$ decreases by $32.4 \%, 55.9 \%, 78.7 \%$, and $81.7 \%$ for a given $\mathrm{m}_{\mathrm{f}}$ at $0 \%, 10 \%, 20 \%$, and $30 \%$, respectively. This is attributed to the fact that a larger $\mathrm{w} / \mathrm{b}$ will result in a larger porosity and a smaller resistance to chloride ingress.

\subsection{Experimental Verification}

As can be seen from Equations (13) and (18), $\mu, D_{p}$ and $n$ need to be determined to evaluate $\mathrm{D}_{\mathrm{fc}}$. From the experimental calibration, $\mu$ was obtained as 3.263 [41], which is in excellent agreement with that estimated from the relationship between the critical volume fraction of pores and the aspect ratio [42]. It is appreciated that $D_{p}$ is related to the viscosity of pore solution [21], temperature, and the microstructure of cement paste [43] and is, at present, difficult to measure in the laboratory. As an indirect method, Pivonka et al. [21] and Damrongwiriyanupap et al. [30] obtained through experimental calibration the values of $D_{p}$ as $1.07 \times 10^{-10}$ and $1.476 \times 10^{-10} \mathrm{~m}^{2} / \mathrm{s}$, respectively. Since the two values are very close, $D_{p}$ is taken as $1.07 \times 10^{-10} \mathrm{~m}^{2} / \mathrm{s}$ in this paper. Up to now, the percolation exponent $\mathrm{n}$ is still an open issue. For three-dimensional invariable porous media, it has been widely accepted that $\mathrm{n}$ is equal to 2 [44]. Wong et al. [45] demonstrated that $\mathrm{n}$ is between 1.5 and 2 for three-dimensional porous media. For sedimentary rocks with different microstructures, the value of $\mathrm{n}$ calibrated from Archie's law varies from 1.5 to 4 [46]. Oh and Jang [39] showed from experimental 
results that $\mathrm{n}$ is equal to 2.7 for hardened cement paste and increases to 4.5 in the presence of fly ash or slag. They attributed the increase of $\mathrm{n}$ to the improvement of the pore structure caused by mineral admixtures. From the above discussions, it is seen that experimental calibration is possibly the only feasible method. For this purpose, the experimental results obtained in this study for $\mathrm{w} / \mathrm{b}=0.5$ shown in Figure 3 are considered. With these experimental date, $\mathrm{n}$ is back-calculated and regressed, in terms of $\mathrm{m}_{\mathrm{f}}, \alpha_{\mathrm{c}}$ and $\alpha_{\mathrm{f}}$, as

$$
\mathrm{n}=\left(15.13 \mathrm{~m}_{\mathrm{f}}+2.829\right)\left[\mathrm{m}_{\mathrm{f}} \alpha_{\mathrm{f}}+\left(1-\mathrm{m}_{\mathrm{f}}\right) \alpha_{\mathrm{c}}\right]-\frac{76.37 \mathrm{~m}_{\mathrm{f}}+3.914}{37.39 \mathrm{~m}_{\mathrm{f}}^{1.8}+6.614} .
$$

The numerical results show that the correlation coefficient between Equation (20) and the back-calculated values of $\mathrm{n}$ is equal to 0.890 .

With $\mu, D_{p}$, and $n$ known, Equation (18) can be used to evaluate the chloride diffusion coefficient of fly ash cement paste. For $w / b=0.4$ and 0.6 , the result are shown in Figures 4 and 5 , respectively. It is seen from Figures 4 and 5 that the analytical estimate is in good agreement with the experimental results. When $\mathrm{m}_{\mathrm{f}}=0 \%, 10 \%, 20 \%$, and 30\%, the correlation coefficient between them are $0.996,0.984$, 0.987 , and 0.984 for $\mathrm{w} / \mathrm{b}=0.4$ and $0.997,0.959,0.973$, and 0.972 for $\mathrm{w} / \mathrm{b}=0.6$, respectively. Therefore, it is concluded that the EMM can estimate the chloride diffusion coefficient of fly ash cement paste with reasonable accuracy.

\section{Conclusions}

An EMM was proposed to evaluate the chloride diffusion coefficient of fly ash cement paste, and a chloride diffusion test was conducted to investigate the transport properties of fly ash cement paste. The conclusions of this study are summarized in the following points:

1. Fly ash cement paste was modeled as a two-phase material, and the volume fraction of each phase constituent was formulated in terms of the water/binder ratio and the numerically estimated degrees of hydration of cement and fly ash.

2. By considering the percolation characteristics close to the percolation threshold, the percolation theory was incorporated into the EMM and the chloride diffusion coefficient of fly ash cement paste was derived and verified with experimental results.

3. The experimental results show that, when $\mathrm{w} / \mathrm{b}$ was equal to 0.5 and $\mathrm{t}$ was 28 and 540 days, $\mathrm{D}_{\mathrm{fc}}$ at $\mathrm{m}_{\mathrm{f}}=30 \%$ was smaller than that at $\mathrm{m}_{\mathrm{f}}=0 \%$ by $55.7 \%$ and $90.0 \%$, respectively. When $\mathrm{w} / \mathrm{b}$ was equal to 0.5 and $\mathrm{m}_{\mathrm{f}}$ was $0 \%$ and $30 \%, \mathrm{D}_{\mathrm{fc}}$ at 540 days was smaller than that at 28 days by $43.1 \%$ and $86.2 \%$, respectively. When $\mathrm{t}$ was 540 days and $\mathrm{w} / \mathrm{b}$ decreased from 0.6 to $0.4 \mathrm{D}_{\mathrm{fc}}$ decreased by $32.4 \%$ and $81.7 \%$ for $m_{f}=0 \%$ and $30 \%$, respectively.

Author Contributions: Conceptualization, H.Z., X.-Z.Z. and J.-J.Z.; methodology, X.-Z.Z., J.-J.Z. and J.Z.; software, J.Z.; validation, J.Z.; formal analysis, H.Z. and X.-Z.Z.; investigation, H.Z., X.-Z.Z., and J.Z.; writing and editing, H.Z., X.-Z.Z. and J.-J.Z.; visualization, J.Z.; project administration, H.Z. and X.-Z.Z.; funding acquisition, H.Z., X.-Z.Z. and J.-J.Z.

Funding: This research was funded by the National Natural Science Foundation, grant numbers 51878615 and 51779227; the Science and Technology Plan Project of Zhejiang Province, grant number 2016C33106; and the Open Research Fund Program of State key Laboratory of Hydroscience and Engineering, grant Number sklhse-2019-C-01, of China.

Conflicts of Interest: The authors declare no conflict of interest.

\section{References}

1. Buenfeld, N.R.; Glass, G.K.; Hassanein, A.M.; Zhang, J.Z. Chloride transport in concrete subjected to electric field. J. Mater. Civ. Eng. 1998, 10, 220-228. [CrossRef]

2. Cady, P.D.; Weyers, R.E. Deterioration rates of bridge concrete decks. J. Transp. Eng. 1984, 110, 34-44. [CrossRef] 
3. Liam, K.C.; Roy, S.K.; Northwood, D.O. Chloride ingress measurements and corrosion potential mapping study of a 24-year-old reinforced-concrete jetty structure in a tropical marine environment. Mag. Concr. Res. 1992, 44, 205-215. [CrossRef]

4. MacDonald, K.A.; Northwood, D.O. Experimental measurements of chloride ion diffusion rates using a two-compartment diffusion cell: Effects of material and test variables. Cem. Concr. Res. 1995, 25, 1407-1416. [CrossRef]

5. De Weerdt, K.; Colombo, A.; Coppola, L.; Justnes, H.; Geiker, M.R. Impact of associated cation on chloride binding of Portland cement paste. Cem. Concr. Res. 2015, 68, 196-202. [CrossRef]

6. Thomas, M.D.A.; Shehata, M.H.; Shashiprakash, S.G.; Hopkins, D.S.; Cail, K. Use of ternary cementitious systems containing silica fume and fly ash in concrete. Cem. Concr. Res. 1999, 29, 1207-1214. [CrossRef]

7. Chindaprasirt, P.; Jaturapitakkul, C.; Sinsiri, T. Effect of fly ash fineness on compressive strength and pore size of blended cement paste. Cem. Concr. Compos. 2005, 27, 425-428. [CrossRef]

8. Coppola, L.; Coffetti, D.; Crotti, E. Plain and ultrafine fly ashes mortars for environmentally friendly construction materials. Sustainability 2018, 10, 874. [CrossRef]

9. Coppola, L.; Coffetti, D.; Crotti, E. Rheological and physical performances of mortars manufactured with plain and ultrafine fly ashes. ACI Spec. Publ. 2018, 326, 32.

10. Zheng, J.J.; Zhou, X.Z. Three-phase composite sphere model for the prediction of chloride diffusion coefficient of concrete. J. Mater. Civ. Eng. 2008, 20, 205-211. [CrossRef]

11. Page, C.L.; Short, N.R.; Tarra, A.E. Diffusion of chloride ions in hardened cement pastes. Cem. Concr. Res. 1981, 11, 395-406. [CrossRef]

12. Castellote, M.; Alonso, C.; Andrade, C.; Chadbourn, G.A.; Page, C.L. Oxygen and chloride diffusion in cement pastes as a validation of chloride diffusion coefficients obtained by steady-state migration tests. Cem. Concr. Res. 2001, 31, 621-625. [CrossRef]

13. Tang, L.P.; Nilsson, L.O. Rapid determination of chloride diffusivity in concrete by applying an electrical field. ACI Mater. J. 1992, 89, 49-53.

14. Lu, X.Y. Application of the Nernst-Einstein equation to concrete. Cem. Concr. Res. 1997, 27, $293-302$. [CrossRef]

15. Ampadu, K.O.; Torii, K.; Kawamura, M. Beneficial effect of fly ash on chloride diffusivity of hardened cement paste. Cem. Concr. Res. 1999, 29, 585-590. [CrossRef]

16. Ngala, V.T.; Page, C.T. Effects of carbonation on pore structure and diffusional properties of hydrated cement pastes. Cem. Concr. Res. 1997, 27, 995-1007. [CrossRef]

17. Chalabi, H.; Khelidj, A.; Bezzar, A. Chloride transport in partially saturated cementitious material: Influence of hydric state and binding chloride. Mag. Concr. Res. 2017, 69, 1103-1114. [CrossRef]

18. Ramirez-Ortiz, A.E.; Castellanos, F.; Cano-Barrita, P.F.D. Ultrasonic detection of chloride ions and chloride binding in Portland cement pastes. Int. J. Concr. Struct. Mater. 2018, 12, UNSP 20. [CrossRef]

19. Akhavan, A.; Rajabipour, F. Evaluating ion diffusivity of cracked cement paste using electrical impedance spectroscopy. Mater. Struct. 2013, 46, 697-708. [CrossRef]

20. Millar, S.; Kruschwitz, S.; Wilsch, G. Determination of total chloride content in cement pastes with laser-induced breakdown spectroscopy (LISB). Cem. Concr. Res. 2019, 117, 16-22. [CrossRef]

21. Pivonka, P.; Hellmich, C.; Smith, D. Microscopic effects on chloride diffusivity of cement pastes-A scale-transition analysis. Cem. Concr. Res. 2004, 34, 2251-2260. [CrossRef]

22. Zheng, J.J.; Zhou, X.Z. Analytical solution for the chloride diffusivity of hardened cement paste. J. Mater. Civ. Eng. 2008, 20, 384-391. [CrossRef]

23. Garboczi, E.J.; Bentz, D.P. Computer simulation of the diffusivity of cement-based materials. J. Mater. Sci. 1992, 27, 2083-2092. [CrossRef]

24. Masi, M.; Colella, D.; Radaelli, G.; Bertolini, L. Simulation of chloride penetration in cement-based materials. Cem. Concr. Res. 1997, 27, 1591-1601. [CrossRef]

25. Liu, L.; Sun, W.; Ye, G.; Chen, H.S.; Qian, Z.W. Estimation of the ionic diffusivity of virtual cement paste by random walk algorithm. Constr. Build. Mater. 2012, 28, 405-413. [CrossRef]

26. Ma, H.Y.; Hou, D.S.; Li, Z.J. Two-scale modeling of transport properties of cement paste: Formation factor, electrical conductivity and chloride diffusivity. Comput. Mater. Sci. 2015, 110, 270-280. [CrossRef]

27. Du, X.L.; Jin, L.; Zhang, R.B. Chloride diffusivity in saturated cement paste subjected to external mechanical loading. Ocean Eng. 2015, 95, 1-10. [CrossRef] 
28. Yang, Y.K.; Patel, R.A.; Churakov, S.V.; Prasianakis, N.I.; Kosakowshi, G.; Wang, M.R. Multiscale modeling of ion diffusion in cement paste: Electrical double layer effect. Cem. Concr. Compos. 2019, 96, 55-65. [CrossRef]

29. Carrara, P.; De Lorenzis, L.; Wu, T. Chloride diffusivity of hardened cement paste from multiscale modeling. Spec. Publ. 2015, 305, 6.

30. Damrongwiriyanupap, N.; Scheiner, S.; Pichler, B.; Hellmich, C. Self-consistent channel approach for upscaling chloride diffusivity in cement pastes. Transp. Porous Med. 2017, 118, 495-518. [CrossRef]

31. Parrot, L.J.; Killoh, D.C. Prediction of cement hydration. Br. Ceram. Proc. 1984, 35, 41-53.

32. Wang, X.Y.; Lee, H.S. Modeling the hydration of concrete incorporating fly ash or slag. Cem. Concr. Res. 2010, 40, 984-996. [CrossRef]

33. Papadakis, V.G. Effect of fly ash on Portland cement systems: Part I. low-calcium fly ash. Cem. Concr. Res. 1999, 30, 1647-1654. [CrossRef]

34. Haha, M.B.; De Weerdt, K.; Lothenbach, B. Quantification of the degree of reaction of fly ash. Cem. Concr. Res. 2010, 40, 1620-1629. [CrossRef]

35. Hansen, T.C. Physical structure of hardened cement paste: A classical approach. Mater. Struct. 1986, 19, 423-436. [CrossRef]

36. Yu, Z.Q. Microstructure Development and Transport Properties of Portland Cement-Fly Ash Binary Systems: In View of Service Life Predictions. Ph.D. Thesis, Delft University of Technology, Delft, The Netherlands, 2015.

37. Torquato, S. Random Heterogenerous Materials: Microstructure and Macroscopic Properties; Springer: New York, USA, 2001.

38. Cai, W.Z.; Tu, S.T.; Gong, J.M. A physically based percolation model of the effective electrical conductivity of particle filled composites. J. Compos. Mater. 2006, 40, 2131-2142. [CrossRef]

39. Oh, B.H.; Jang, S.Y. Prediction of diffusivity of concrete based on simple analytic equations. Cem. Concr. Res. 2004, 34, 463-480. [CrossRef]

40. Liu, J.; Wang, X.D.; Qiu, Q.W.; Ou, G.F.; Xing, F. Understanding the effect of curing age on the chloride resistance of fly ash blended concrete by rapid chloride migration test. Mater. Chem. Phys. 2017, 196, 315-323. [CrossRef]

41. Zheng, J.J.; Zhou, X.Z.; Wu, Z.M. A simple method for predicting the chloride diffusivity of cement paste. Mater. Struct. 2010, 43, 99-106. [CrossRef]

42. Garboczi, E.J.; Snyder, K.A.; Douglas, J.F. Geometrical percolation threshold of overlapping ellipsoids. Phys. Rev. E 1995, 52, 819-828. [CrossRef]

43. Atkinson, A.; Nickerson, A.K. The diffusion of ions through water-saturated cement. J. Mater. Sci. 1984, 19, 3068-3078. [CrossRef]

44. Nan, C.W. Physics of inhomogeneous inorganic materials. Prog. Mater. Sci. 1993, 37, 1-116. [CrossRef]

45. Wong, P.A.; Koplik, J.; Tomanic, J.P. Conductivity and permeability of rocks. Phys. Rev. B 1984, 30, 6606-6614. [CrossRef]

46. Archie, G.E. The electrical resistivity log as an aid in determining some reservoir characteristics. Well Logging Technol. 1942, 146, 54-62. [CrossRef]

(c) 2019 by the authors. Licensee MDPI, Basel, Switzerland. This article is an open access article distributed under the terms and conditions of the Creative Commons Attribution (CC BY) license (http://creativecommons.org/licenses/by/4.0/). 